\author{
Marta Borowiak-Dostatnia \\ Anna Zięba \\ Uniwersytet im. Adama Mickiewicza, Poznań
}

\title{
ANALIZA WYBRANYCH PROJEKTÓW UNIJNYCH JAKO WYRAZ ZAANGAŻOWANIA PAŃSTW UE W ROZWÓJ NARZĘDZI ICT I TECHNOLOGII JĘZYKOWYCH W NAUCZANIU JĘZYKÓW OBCYCH
}

\begin{abstract}
The paper presents a sample of analysis of EU project with regard to ICT application in foreign language teaching and language technology. The analysis is based upon the authors' observation that by exploring a number of at least 75 projects in terms of their participants, framework programs and scope, some general tendencies can be revealed. The tendencies concern EU research and member state engagement in the aforementioned fields. Having analyzed the data the authors define the nature of the studied projects (educational vs. scientific), point to the most active and beneficial member states and draw models of public and private units cooperation in European research consortiums. Additionally, the analysis presents the first step for further study with regard to particular ICT-tool usage in foreign language learning/teaching in a particular EU country.
\end{abstract}

\section{Wstęp}

W historii Unii Europejskiej lata 90. to nie tylko proces konsolidacji i prawnoadministracyjne ukształtowanie Wspólnoty, ale również czas określenia nowych kierunków działań politycznych i gospodarczo-ekonomicznych. UE - wzorując się na poczynaniach USA i Japonii - swoje działania skierowała na rozwój i zastosowanie technologii oraz wykorzystanie potencjału narzędzi ICT (Informa- 
tion and Communication Technologies). Elementy te stanowić miały siłę napędową sektora gospodarczego w nadchodzących latach. Początek zmian wiąże się z tzw. raportem Bangemanna ${ }^{1}$ przedstawionym Radzie Europejskiej w 1994 roku. Echem zawartych w nim postulatów były dokumenty wyznaczajace nowe cele działań (np. Growth, Competitiveness, Employment: The Challenges and Ways Forward into the 21 st Century - White Paper ${ }^{2}$ ), cykl programów rozwojowych eEurope realizowanych w ramach strategii lizbońskiej, sama strategia oraz programy naukowo-badawcze takie jak 5 Program Ramowy i dalsze. Wspólnym mianownikiem wszystkich przywołanych jest koncentracja na jak najszerszym zastosowaniu technologii informacyjno-komunikacyjnych (ICT).

W niniejszym artykule zastosowanie to zostało zawężone do prac związanych z wykorzystaniem rozwiązań technologicznych w języku oraz do języka jako systemu w narzędziach typu ICT. Rozwiązania te, a właściwie ich znajomość powinna mieć przełożenie na jakość i adekwatność nauczania języków obcych, w tym nauczania dorosłych. Analiza projektów unijnych ma na celu wykazać:

1. W jakiego typu projektach połączono język i technologię oraz jakie są efekty tego połączenia?

2. Jakie kraje uczestniczyły w projektach i w jakiej roli: koordynatora czy uczestnika?

3. Jaka jest aktywność poszczególnych państw UE w zakresie wykorzystania rozwiązań technologicznych do pracy z językiem?

4. Jakiego typu organizacje/podmioty były częścią konsorcjum?

5. Jak zaprezentowana analiza może wpłynać na proces kształcenia dorosłych w zakresie nauczania języków obcych?

\section{Analiza projektów unijnych a rola technologii w nauczaniu języków obcych w odniesieniu do dorosłych}

Nie jest celem niniejszego artykułu przedstawianie najważniejszych metodycznych i glottodydaktycznych aspektów nauczania dorosłych dostępnych w literaturze przedmiotu, dlatego poniższa część teoretyczna poruszy tylko wybrane przez autorki problemy z tego szerokiego zagadnienia.

Konkretniej, uwaga skierowana zostanie na rozwiązania technologiczne, które powstały w wyniku zaangażowania w projekty unijne konkretnych państw członkowskich. W ten sposób spróbujemy odpowiedzieć na pytanie, który kraj jest naj-

\footnotetext{
${ }^{1}$ High-level Group chaired by European Commissioner Martin Bangemann, Europe and the Global Information Society Bangemann report recommendations to the European Council, http:// ec.europa.eu/archives/ISPO/infosoc/backg/bangeman.html\#action_plan DW 01.10.2010. ${ }^{2}$ Growth, Competitiveness, Employment: The Challenges and Ways Forward into the 21st Century White Paper, Parts A and B. COM (93) 700 final/A and B, 5 December 1993. Bulletin of the European Communities, Supplement 6/93, http://aei.pitt.edu/1139/ DW 01.10.2010.
} 
bardziej zaangażowany w opracowanie nowych narzędzi ICT, w tym narzędzi glottodydaktycznych oraz jaką przyjąć perspektywę rozważając o nauczaniu dorosłych.

W tym kontekście warto inaczej spojrzeć na tą grupę osób. Jak wspomniano, w artykule skupiamy się głównie na aspektach dotyczących technologii w nauczaniu. Potraktujmy zatem dorosłych jako grupę osób, która posiada pewne umiejętności z zakresu IT (czyli posługiwania się komputerem, aplikacjami internetowymi oraz innymi narzędziami technologicznymi). Pomocny w takim ujęciu dorosłych uczniów jest termin Digital Immigrants zastosowany i spopularyzowany przez Marca Prensky’ego (Prensky M. 2001). Definiując pojęcie, należy przywołać słowa autora, który mówi, że:

Those of us who were not born into the digital world but have, at some later point in our lives, become fascinated by and adopted many or most aspects of the new technology are (...) Digital Immigrants. (...) As Digital Immigrants learn (...) to adapt to their environment, they always retain, to some degree, their ,accent”, that is, their foot in the past. There are hundreds of examples of the digital immigrant accent. They include printing out your email (...); needing to print out a document written on the computer in order to edit it (rather than just editing on the screen); and bringing people physically into your office to see an interesting web site (rather than just sending them the URL). ${ }^{3}$

Termin ten wykorzystany był w kontekście nauczycieli języków obcych jako tych, którzy muszą dostosować tradycyjne metody nauczania do wymogów wspó1czesnego, skomputeryzowanego świata ${ }^{4}$. Wydaje się jednak, że z powodzeniem można go również zastosować do charakteryzowanych tu uczniów, którzy przecież stanowią zróżnicowaną pod względem wieku grupę. Ich umiejętności z zakresu IT są w tym wypadku sprawą kluczową i przy wyborze odpowiedniego narzędzia z

3 Prensky M. 2001, Digital Natives, Digital Immigrants, On the Horizon, MCB University Press, Vol. 9 No. 5, October 2001 http://www.marcprensky.com/ DW 09.03.2010.

4 Termin pojawił się w 2001 roku i wywołał dyskusję wśród osób zajmujących się zastosowaniem technologii w nauczaniu języków obcych. Uważano, że podział na Digital Natives (uczniowie) vs. Digital Immigrants (nauczyciele) jest zbyt prosty i powierzchowny. Słowa krytyki odnajdziemy m.in. w Guo R. X., Dobson T., Petrina S. 2008, Digital Natives, Digital Immigrants: An Analysis of Age and ICT Competency in Teacher Education, Journal of Educational Computing Research, v38 n3 s. 235-254, 2008 http://baywood.metapress.com/link.asp? target=contribution\&id=Q4565NG624514844 DW 01.06.2011, Kennedy, G., Dalgarno, B., Bennett, S., Judd, T., Gray, K. \& Chang, R. 2008, Immigrants and natives: Investigating differences between staff and students' use of technology. (w:) Hello! Where are you in the landscape of educational technology? Proceedings ascilite Melbourne 2008. http:/ /www.ascilite.org.au/conferen ces/melbourne08/procs/kennedy.pdf DW 08.03.2010, Bayne S., Ross J. 2007, The 'digital native' and 'digital immigrant': a dangerous opposition, Annual Conference of the Society for Research into Higher Education (SRHE) 12.2007, http://www.malts.ed.ak.uk DW 01.06.2011, Holton D. 2010, The Digital Natives/Digital Immigrants Distinction Is Dead, Or At Least Dying, EdTechDev developing educational technology, http://edtechdev.wordpress.com/2010/03/19/the-digitalnatives-digital-immigrants-distinction-is-dead-or-at-least-dying/ DW 01.06.2011. 
grupy ICT fakt ten należy wziąć pod uwagę. Wprowadzenie platformy elearningowej, komunikatorów, portali społecznościowych czy podcastów jako narzędzi pracy mija się z celem, jeżeli uczeń nie potrafi z nich efektywnie korzystać.

Należy zwrócić uwagę na jeszcze jeden aspekt nauki języka obcego przez dorosłych. Dane Eurobarometru z 2006 roku wskazują, iż uczniowie ci podejmują naukę głównie z powodów praktycznych, takich jak: możliwość komunikowania sie na wakacjach - 35\% lub aby postugiwać sie nim w pracy (podczas wyjazdów stu̇̇bowych) $-32 \%$. Znajomość tych danych powinna wpłynąć na konstrukcję procesu dydaktycznego ukierunkowanego na ucznia dorosłego. Uwzględnienie motywacji lub jej braku pozwala na odpowiedni dobór narzędzi dydaktycznych. Z danych dostarczonych przez UE wiemy, że czynnikami zniechęcającymi są przede wszystkim brak czasu - 34\%, brak odpowiedniej motywacij - 30\% oraz wydatki zwiqzane z nauk - 22\% $\%^{6}$. Zastosowanie odpowiednich narzędzi ICT mogłoby stać się elementem zmniejszającym odsetek w każdej kategorii ${ }^{7}$. Dlatego rozwiązania technologiczne w tym głównie platformy e-learningowe i komunikatory bardzo dobrze wpisują się w zakres czynników motywujących do nauki.

W skali Europy zasadne jest zadać pytanie, jakiego rodzaju narzędzia mamy do wyboru oraz gdzie i jak sa one budowane. Przedstawiona w artykule analiza, choć bezpośrednio pokazuje zaangażowanie państw członkowskich w zastosowanie technologii do pracy z językiem, w sposób pośredni może wskazać narzędzia i aktywność poszczególnych członków w proces tworzenia nowych rozwiązań technologicznych w zakresie nauczania języków obcych. W badaniach zlecanych przez UE nie znajdziemy gruntownych opracowań lub case study, które łączą kwestie technologii i nauczania dorosłych języków obcych. Jedyne dostępne raporty to: The Impact of New Information Technologies and Internet on the Teaching of Foreign Languages and the Role of Teachers of a Foreign Language (2002) ${ }^{8}$ traktujacy o zastosowaniu narzędzi ICT na różnych poziomach szkolnictwa, w tym nauczania dorosłych w Danii i Niemczech oraz Francji; oraz Study on the Impact of Information and Communications Technology (ICT) and New Media on Language Learning (2009)9 dotyczacy zastosowania technologii w nauczaniu języków obcych. A zatem UE nie pro-

\footnotetext{
${ }^{5}$ EUROBAROMETR 243 2005, Europejcsycy i ich jezylki. Podsumowanie, http:/ / ec.europa.eu /public_opinion/archives/ebs/ebs_243_sum_pl.pdf DW 29.08.2008.

6 Tamże.

${ }^{7}$ Przedstawiony pogląd ma charakter hipotezy i wymaga dalszych, bardziej szczegółowych badań. W mniemaniu autorek można jednak w tym miejscu taką hipotezę postawić.

${ }^{8}$ Directorate General Education and Culture at the European Commission 2002, The Impact of Information and Communications Technologies on the Teaching of Foreign Languages and on the Role of Teachers of Foreign Languages, http://ec.europa.eu/education/policies/lang/doc /ict.pdf DW 01.03.2010.

${ }^{9}$ Education and Culture Executive Agency (EACEA) 2009, Study on the Impact of Information and Communications Technology (ICT) and New Media on Language Learning, Ellinogermaniki Agogi, http://eacea.ec.europa.eu/.../study_impact_ict_new_media_language_ learning/executive_summary_en.pdf DW 02.07.2010.
} 
Analiza wybranych projektów unijnych jako wyraz zaangażowania państw UE...

wadzi regularnych badań związanych z nauczaniem dorosłych i wykorzystaniem narzędzi ICT. Pewien obraz nakreśla przedstawiona poniżej analiza.

\section{Obiekt i metody badań}

Analizę przeprowadzono na 75 projektach unijnych, będących tym samym obiektem badań ${ }^{10}$. Ilościowy charakter analizy przejawia się głównie w liczebności projektów uwzględniających ich edukacyjny i naukowy charakter oraz w liczbie podmiotów w nich uczestniczących. Przez charakter edukacyjny rozumie się produkty skoncentrowane na zastosowaniu ICT i platform e-learningowych w nauczaniu języków obcych, opracowanie interaktywnych modułów szkoleniowych w tym zakresie itp; przez naukowy zaś prace z obszaru technologii językowych, językoznawstwa komputerowego oraz tłumaczenia mechanicznego. Jakościowy charakter analizy dotyczy przede wszystkim wspomnianego typu projektów i produktów końcowych.

Głównym i w zasadzie jedynym kryterium wyboru projektów była ich tematyka, która koncentrowała się na powiązaniu technologii i języka. Projekty zrealizowane były, lub zaczęto ich realizację, w latach 2000-2010. Źródła informacji i podstawowe dane na temat wykorzystanego programu, czasu realizacji i konsorcjum pochodziły z oficjalnych stron Unii Europejskiej, takich jak: European Commission, Cordis: 7FP: ICT: Language Technologies ${ }^{11}$, International Cooperation, Participation in EU Education and Training Programmes ${ }^{12}$, Euro Languages Net, Lingua Porducts Fair ${ }^{13}$; oraz oficjalnych stron samych projektów. Badanie przeprowadzono w okresie od 01.06.2010 do 30.09.2010 roku.

\section{Przegląd wybranych projektów}

Analizę zilustrowano w formie tabelarycznej, uwzględniając nazwę projektu i czas jego realizacji, program unijny, kraje biorące udział w przedsięwzięciu z podziałem na koordynatora i uczestnika, tematykę projektu oraz rezultat (produkt końcowy).

Uszeregowanie chronologiczne (począwszy od najnowszych projektów) pozwoliło wyraźnie określić kierunek polityki Unii w zakresie zastosowania technologii w języku w konkretnych latach i programach rozwojowych. Uwzględnienie w analizie kraju uczestniczącego wraz z określeniem jego funkcji,

\footnotetext{
10 Przedstawiona analiza i komentarz do niej stanowi część badań jednej z autorek prowadzonych w ramach pracy nad rozprawą doktorską.

${ }^{11}$ European Commission, Cordis: 7FP: ICT: Language Technologies, http://cordis.europa.eu /fp7/ict/language-technologies/portfolio_en.html DW 01.06.2010.

12 International Cooperation, Participation in EU Education and Training Programmes, http:/ / internet.ktu.lt/en/kut/trysiai/LLP_projects.html DW 01.06.2010.

${ }^{13}$ Euro Languages Net, Lingua Products Fair, http:/ /www.euro-languages.net/sdm/?Com mand=LPF DW 01.06.2010.
} 
dało podstawy do oceny aktywności danego państwa w badanym zakresie oraz na bardziej szczegółowym poziomie analizy wykazało, jakiego typu podmioty (publiczne vs. komercyjne) są uczestnikami unijnych projektów naukowobadawczych. Z kolei tematyka projektu oraz jego efekt końcowy służyły do zaklasyfikowania go jako edukacyjny lub naukowy.

Ze względów objętościowych artykułu, poniżej (tabela 1) przedstawiono jedynie fragment (10 z 75 projektów) reprezentacji tabelarycznej.

\section{Wyniki analizy}

Tabelaryczna prezentacja analizy pozwoliła na określenie tendencji, o których w formie pytań wspomniano we wstępnej części artykułu.

\subsection{Charakter analizowanych projektów}

Odpowiadając zatem na pytanie dotyczące typu projektów, stwierdzić należy, że wykorzystanie technologii i języka łączone jest z dwoma kwestiami. Pierwszą z nich jest rozwój technologii informacyjno-komunikacyjnych w Unii Europejskiej w zakresie technologii językowych ${ }^{14}$; drugą - edukacja. Czym się one charakteryzują?

Otóż zarówno 5, jak i 6 Program Ramowy (ang.: Framework Programme), w zakresie których prowadzone były międzynarodowe projekty badawcze, dużo uwagi poświęcały zagadnieniom związanym z informatyzacją Wspólnoty, z rozwojem robotyki, automatyki, narzędzi ICT, a więc rozwojem skupionym przede wszystkim na handlu elektronicznym dającym wymierne korzyści dla Unii. W ramach tych projektów znalazły się też takie, które łączyły język i technologię (FP5: SpeeCon, INSPIRE, DUMAS, E2M; FP6: DIVINES, QALL-ME, LUNA, DICT). W 7 Programie Ramowym (FP7) zauważono, że zastosowanie technologii w języku pretenduje do osobnej jednostki tematycznej. W ramach nowego zdefiniowania priorytetów badawczych w roku 2009 pojawił się komponent, w obrębie którego można było proponować projekty dotyczące ICT i języka (Objective ICT-2009.4.2: Technology-Enhanced Learning ${ }^{15}$ - Poddziałanie: ICT-2009.4.2: Nauczanie wspomagane technologicznie). Przy kolejnym redefiniowaniu priorytetów na lata 2011-12 poddziałanie zmodyfikowano tak, że wyraźnie było ono ukierunkowane na prowadzenie badań w zakresie technologii językowych ${ }^{16}$ (Objective ICT-2011.4.2 - Lan-

\footnotetext{
${ }^{14} \mathrm{~W}$ literaturze stosuje sie pojęcie technologii językowych i inżynierii językowej, wskazując niekiedy na różnice między pojęciami. Kwestia ta nie zostanie poruszona w niniejszym artykule.

15 European Commission ICT Research in FR7, ICT Challenge 4: Digital Libraries and Content - Intelligent Information Management: Work Programme for 2009-2010, http://cordis.europa.eu/fp7/ict/content-knowledge/fp7_en.html DW 25.09.2010.

${ }_{16} \mathrm{~W} 5 \mathrm{PR}$ i 6PR występowały również poddziałania dotyczące technologii językowych, jednak w 7PR widać zdecydowanie większe zainteresowania tą dyscypliną.
} 
Analiza wybranych projektów unijnych jako wyraz zaangażowania państw UE...

\begin{tabular}{|c|c|c|c|c|c|c|}
\hline & 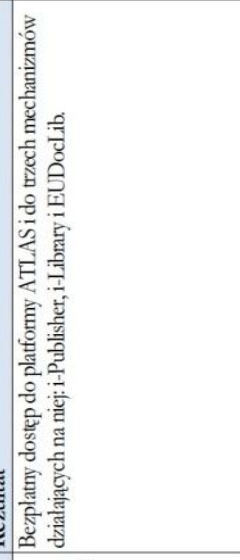 & 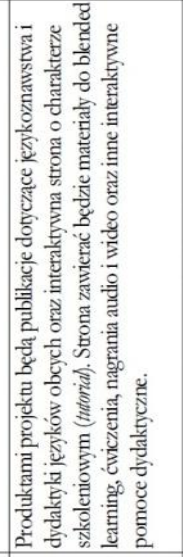 & 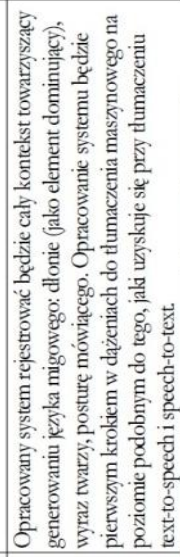 & 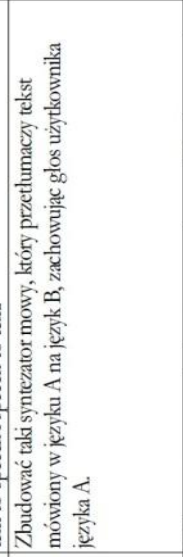 & 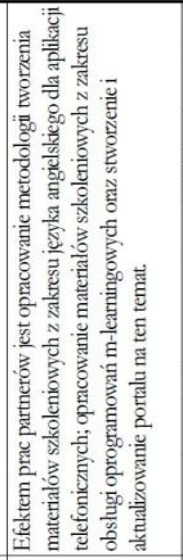 & 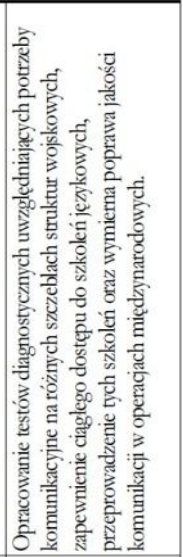 \\
\hline & 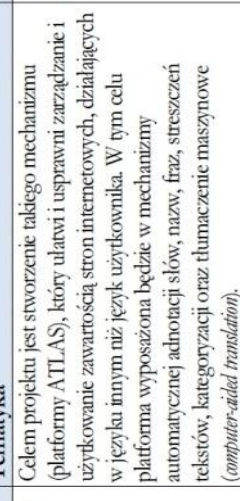 & 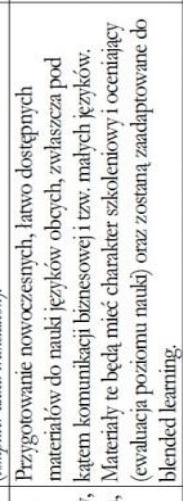 & 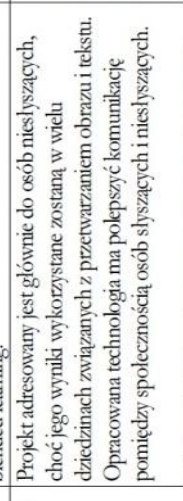 & 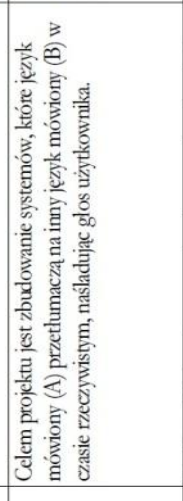 & 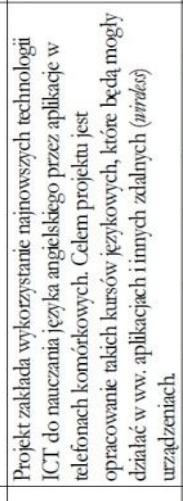 & 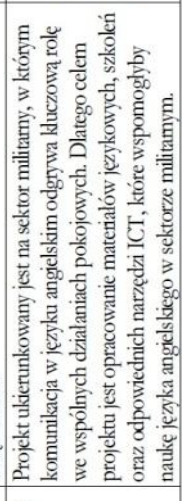 \\
\hline & 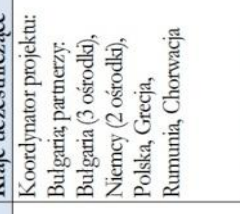 & 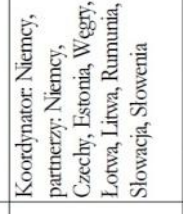 & 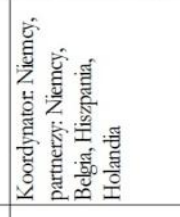 & 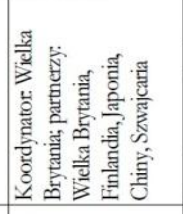 & 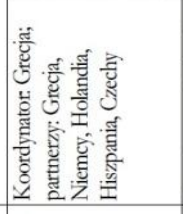 & 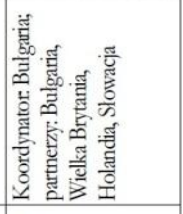 \\
\hline 芯 & 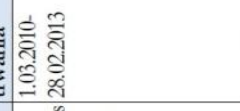 & בิָ & 党 & 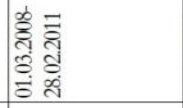 & 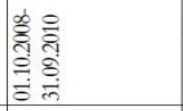 & ন্ \\
\hline & 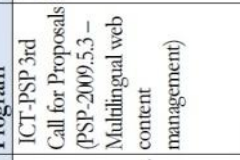 & $\exists$ & 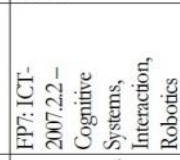 & 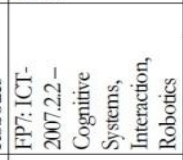 & 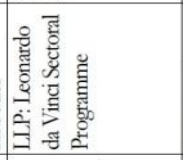 & 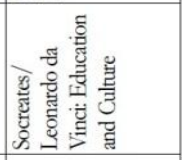 \\
\hline & 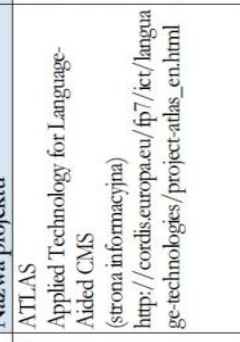 & 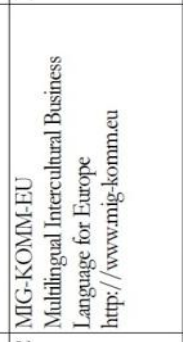 & 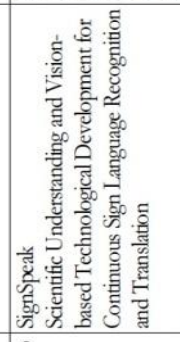 & 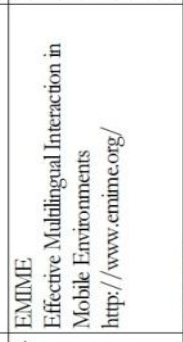 & 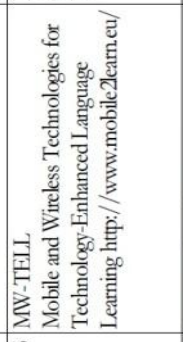 & 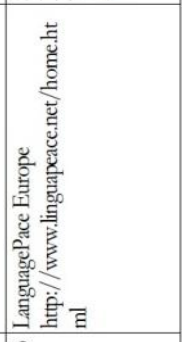 \\
\hline & & & & & & \\
\hline
\end{tabular}




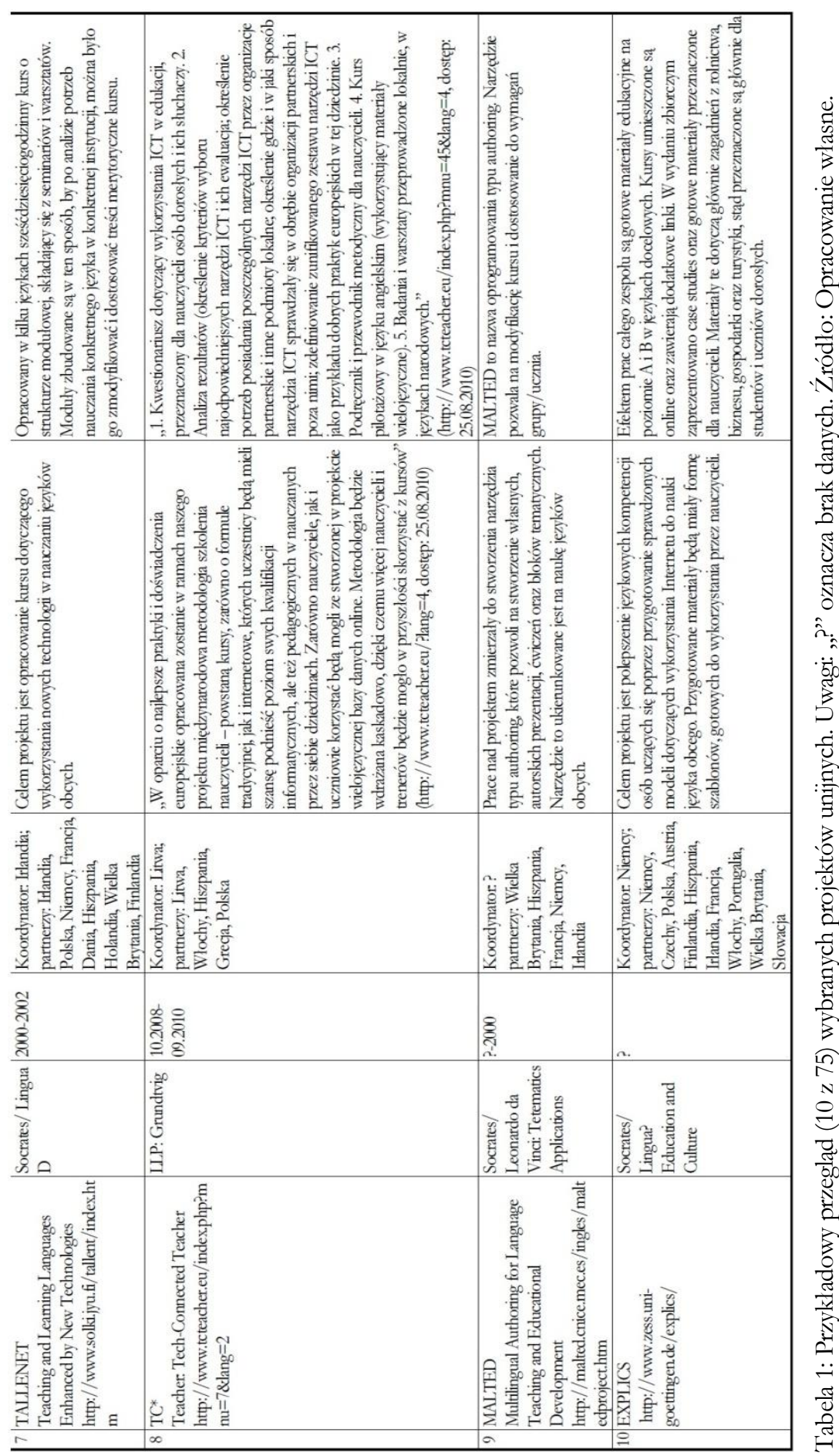


guage Technologies ${ }^{17}$ - Poddziałanie ICT-2011.4.2 - Technologie językowe). Zmiany w programach na lata 2009-10 i 2011-12 zaowocowały zwiększoną liczbą projektów skoncentrowanych na tłumaczeniu maszynowym, na wykorzystaniu metod przetwarzania i syntezy mowy do współpracy z przemysłem, na nowych rozwiązaniach technologicznych wykorzystujących zasoby językowe. Uwagę skierowano na budowanie dużych, wielojęzycznych korpusów językowych, opracowanie nowych modeli ekstrakcji leksykalnych, tworzenie nowych systemów uwzględniajacych zmienne języka, na wypracowanie systemów do automatycznego przetwarzania języka mówionego na tekst i tekstu na język mówiony oraz inne rozwiązania technologiczne, w których język zajmuje centralne miejsce. Można powiedzieć, że o ile w pierwszej połowie dekady projekty zahaczające o język w ramach prac nad ICT należały do mniejszości, to w drugiej połowie i pod jej koniec nastapił zdecydowany wzrost zainteresowania tematyką. Rodzi się pytanie związane z czasem ogłoszenia, czy raczej zredefiniowania priorytetów działań Unii. Dlaczego nie dokonano tego wcześniej? Czy ze względu na bariery technologiczne? Możliwe, że to jest przyczyna, jednak pamiętać należy, że to wzmożone prace naukowców przyczyniają się do zniesienia tych barier. Szybsza modyfikacja działań mogłaby zatem przesunąć o kilka lat rozwiązania, które w chwili obecnej są w fazie rozwoju.

Wydaje się, że na początku dekady Unia w swoich działaniach skoncentrowała się na przygotowaniu obywateli do rozszerzenia Wspólnoty. W związku z tym znaczna część projektów badawczych nastawiona była na aspekt edukacyjny i kulturowy. Położono nacisk na wzajemne zrozumienie i poszanowanie jedności w różnorodności. W kontekście rozwiązań ICT, które w strategii zajmowały kluczowe miejsce, język potraktowany był jako medium komunikacji. Skupiono się na rozwiązaniach e-learningowych oraz narzędziach ICT, które miały wspomóc nauczanie języków obcych. Prace badawcze prowadzone były przede wszystkim w obrębie programów edukacyjnych takich jak Sokrates (oraz jego podprogramów: Minerva, Lingua), a następnie LLP (Lifelong Learning Programme). W realizowanych równolegle 5PR i $6 \mathrm{PR}$ prowadzono również pracę z zakresu technologii językowych (o czym wspomniano wyżej), jednak w zdecydowanej mniejszości. Część z projektów edukacyjnych w ramach komponentu ICT ograniczała się do opracowania prostych modułów promocyjno-informacyjnych zamieszczonych online lub modułów szkoleniowych uwzględniających potrzeby i procedury wprowadzania ICT do nauczania języków obcych. Z czasem jednak zaczęto podchodzić ambitniej do realizacji projektów, pracując nad aplikacjami językowymi, programami czy całymi platformami. Teoretyczny potencjał technologiczny znalazł swoje praktyczne zastosowanie. Można zatem przeprowadzić pewną umowną linię w zakresie przeniesienia zainteresowania Unii, którą jest 7 Program Ramowy. O ile na początku dekady technologia językowa była raczej drugoplanowym polem działań

17 European Commission ICT Research in FR7, Language Technologies: ICT Work Programme 2011-2012, http://cordis.europa.eu/fp7/ict/language-technologies/related-docs _en.html DW 25.09.2010. 
Wspólnoty w porównaniu z ilością proponowanych projektów edukacyjnych, o tyle wraz z ogłoszeniem 7PR proporcje te zostały zamienione.

Warto zauważyć, że zdecydowana większość rozwiązań ICT definiowana jest albo dla języków docelowych (czyli języków partnerów projektu) albo dotyczy konkretnego poziomu nauczania, najczęściej A lub B. Rzadko buduje się narzędzie językowe z myślą o docelowej grupie uczniów. Wyjątkiem są językowe gry komputerowe adresowane najczęściej do uczniów czy młodzieży szkolnej. Profilowane rozwiązania ICT, jeżeli się pojawiaja, mają raczej charakter modułów szkoleniowych dla nauczycieli, a więc ponownie nie są kierowane do konkretnej grupy uczniów.

Tendencję odnośnie do problematyki projektu można zaobserwować na poziomie ogólnoeuropejskim. Nie da się jednak nakreślić kierunku, w którym zmierzałby konkretny kraj w danym przedziale czasowym. Można jedynie prześledzić uczestnictwo poszczególnych państw w analizowanym materiale, co z kolei pozwoli określić aktywność konkretnych członków Unii.

\subsection{Aktywność państw UE w projektach naukowobadawczych}

Poniższe zastawienie ukazuje rolę, w jakiej występował dany kraj w każdym z badanych projektów.

\begin{tabular}{|l|l|l|l|l|l|l|l|}
\hline $\begin{array}{l}\text { W projekcie jako:/ } \\
\text { nazwa kraju }\end{array}$ & Austria & Belgia & Bułgaria & Czechy & Cypr & Dania & Estonia \\
\hline koordynator & 2 & 1 & 2 & 0 & 0 & 1 & 0 \\
\hline uczestnik & 11 & 14 & 13 & 20 & 4 & 10 & 8 \\
\hline
\end{tabular}

\begin{tabular}{|l|l|l|l|l|l|l|l|}
\hline $\begin{array}{l}\text { W projekcie jako:/ } \\
\text { nazwa kraju }\end{array}$ & Finlandia & Francja & Grecja & Hiszpania & Holandia & Irlandia & Litwa \\
\hline koordynator & 2 & 7 & 5 & 2 & 3 & 3 & 6 \\
\hline uczestnik & 20 & 17 & 15 & 34 & 19 & 14 & 11 \\
\hline
\end{tabular}

\begin{tabular}{|l|l|l|l|l|l|l|l|}
\hline $\begin{array}{l}\text { W projekcie jako:/ } \\
\text { nazwa kraju }\end{array}$ & Luksemburg & Lotwa & Malta & Niemcy & Polska & Portugalia & Rumunia \\
\hline koordynator & 0 & 2 & 0 & 13 & 0 & 1 & 1 \\
\hline uczestnik & 2 & 10 & 7 & 35 & 19 & 7 & 14 \\
\hline
\end{tabular}

\begin{tabular}{|l|l|l|l|l|l|l|l|}
\hline $\begin{array}{l}\text { W projekcie jako:/ } \\
\text { nazwa kraju }\end{array}$ & Słowacja & Słowenia & Szwecja & Wegry & $\begin{array}{l}\text { Wielka } \\
\text { Brytania }\end{array}$ & Włochy & \\
\hline koordynator & 0 & 0 & 2 & 2 & 7 & 6 \\
\hline uczestnik & 9 & 12 & 9 & 13 & 34 & 19 & \\
\hline
\end{tabular}

Tabela 2: Aktywność państw UE w projektach z uwzględnieniem roli (koordynatora vs. Uczestnika). Źródło: Opracowanie własne.

Aktywność w projekcie rozpatrywano pod kątem koordynatora i uczestnika projektu. W sytuacji, gdy w projekcie uczestniczyło wiele podmiotów z tego 
samego kraju, kraj ten liczony był jednorazowo. Podobnie, gdy to samo państwo było i koordynatorem i uczestnikiem (udział brało wiele podmiotów), państwo to zaliczano do kategorii koordynatora. W ten sposób na przykładzie 75 projektów wyciagnąć można wnioski, co do najbardziej zaangażowanych w badania nad połączeniem technologii i języka członków Unii.

Analiza wykazała, że bezsprzecznie liderem są Niemcy. Zarówno pod względem ilości realizowanych projektów (uczestnik: 35), jak również pod względem inicjowania i zawiązywania zespołów badawczych (koordynator: 13). Ogólnie Niemcy były partnerem w 48 z 76 przebadanych projektów, co stanowi $63 \%$ uczestnictwa we wszystkich badaniach. Drugie miejsce zajęła Wielka Brytania, uczestnicząca w 41 projektach (koordynator: 7, uczestnik: 34), co daje również wysoki wskaźnik pod względem występowania w ogólnej liczbie projektów: ponad 53\%; trzecie zaś Hiszpania, która brała udział w 36 projektach (koordynator: 2 , uczestnik: 34 ) z ponad $47 \%$ udziałem w całości. W drugiej grupie, w której udział w projektach pod względem koordynatora i uczestnika mieścił się w przedziale 20-29 znalazły się: Czechy, Finlandia, Francja, Grecja, Holandia oraz Włochy. Należy zauważyć, że pomiędzy Hiszpanią a Włochami, czyli krajami zajmującymi dwie skrajne pozycje w swoich grupach jest przewaga $15 \%$ równowartym uczestnictwu w 11 projektach. Tak więc różnica w tych dwóch grupach jest duża. Trzecią i najliczniejsza grupe stanowia państwa w przedziale 10-19. Sa nimi: Austria, Belgia, Bułgaria, Dania, Irlandia, Litwa, Łotwa, Polska, Rumunia, Słowenia, Szwecja oraz Węgry. Do czwartej grupy (0-9), zaklasyfikowano: Cypr, Estonię, Luksemburg, Maltę, Portugalię oraz Słowację. Cypr i Malta ze względu na obiektywne ograniczenia w postaci powierzchni terytorialnej musiały znaleźć się w jednej z ostatnich grup. Biorąc ten fakt pod uwagę, ich wynik jest całkiem dobry w porównaniu z Luksemburgiem, który podobnie będąc jednym z najmniejszych państw UE wykazuje minimalną aktywność.

\subsection{Podmioty zaangażowane $\mathrm{w}$ projekty unijne}

Analiza podmiotów biorących udział w projektach pozwoliła określić tendencję w zakresie zainteresowania danego państwa obszarem badań, tu zawężonym do technologii językowych i rozwiązań technologicznych w zakresie nauczania języków obcych.

Podmioty te podzielono na publiczne, czyli uniwersytety, politechniki, instytuty, państwowe ośrodki naukowo-badawcze; oraz komercyjne, do których zaliczono firmy, stowarzyszenia i organizacje non-profit, jak również jednostki badawcze z innym niż państwowe źródło finansowania. 
Marta Borowiak-Dostatnia, Anna Zięba

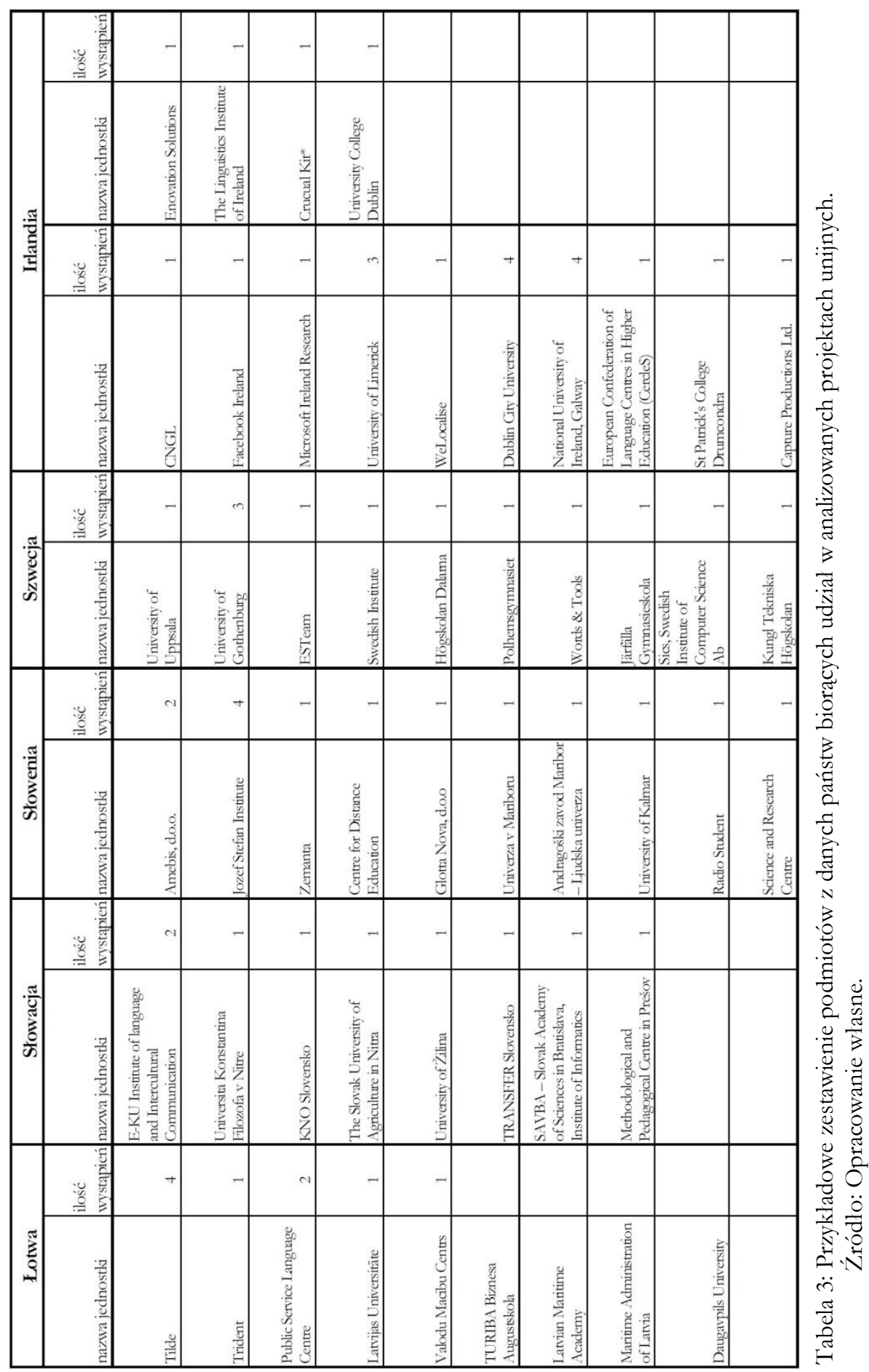


Analiza wybranych projektów unijnych jako wyraz zaangażowania państw UE...

Pod względem ilościowym, udział odpowiedniego podmiotu w konkretnym państwie kształtował się następująco:

\begin{tabular}{|l|l|l|l|l|l|l|l|}
\hline $\begin{array}{l}\text { W projekcie jako:/nazwa } \\
\text { kraju }\end{array}$ & Austria & Belgia & Bułgaria & Czechy & Cypr & Dania & Estonia \\
\hline podmioty komercyjne & 5 & 9 & 8 & 8 & 3 & 3 & 2 \\
\hline podmioty publiczne & 6 & 4 & 6 & 7 & 1 & 3 & 1 \\
\hline
\end{tabular}

\begin{tabular}{|l|l|l|l|l|l|l|l|}
\hline $\begin{array}{l}\text { W projekcie jako:/nazwa } \\
\text { kraju }\end{array}$ & Finlandia & Francja & Grecja & Hiszpania & Holandia & Irlandia & Litwa \\
\hline podmioty komercyjne & 18 & 30 & 11 & 31 & 19 & 8 & 7 \\
\hline podmioty publiczne & 8 & 5 & 6 & 10 & 8 & 6 & 6 \\
\hline
\end{tabular}

\begin{tabular}{|l|l|l|l|l|l|l|l|}
\hline $\begin{array}{l}\text { W projekcie jako:/nazwa } \\
\text { kraju }\end{array}$ & Luksemburg & Lotwa & Malta & Niemcy & Polska & Portugalia & Rumunia \\
\hline podmioty komercyjne & 2 & 6 & 1 & 45 & 11 & 1 & 9 \\
\hline podmioty publiczne & 0 & 3 & 1 & 25 & 8 & 5 & 4 \\
\hline
\end{tabular}

\begin{tabular}{|l|l|l|l|l|l|l|l|}
\hline $\begin{array}{l}\text { W projekcie jako:/nazwa } \\
\text { kraju }\end{array}$ & Słowacja & Słowenia & Szwecja & Węgry & $\begin{array}{l}\text { Wielka } \\
\text { Brytania }\end{array}$ & Włochy & \\
\hline podmioty komercyjne & 3 & 6 & 4 & 10 & 13 & 21 \\
\hline podmioty publiczne & 5 & 4 & 4 & 5 & 26 & 8 & \\
\hline
\end{tabular}

Tabela 4: Udział podmiotów komercyjnych vs. publicznych w analizowanych projektach. Źródło: Opracowanie własne.

Porównując podmioty publiczne z komercyjnymi, prześledzić można prawdopodobny kierunek działań konkretnych państw. Pamiętać jednak należy, że w większości przypadków w skład konsorcjum, które ubiega się o grant unijny musi wchodzić jednostka naukowo-badawcza. Stąd obecność instytutu, uniwersytetu czy politechniki w każdym projekcie jest oczywista. Również niewątpliwa jest współpraca kilku podmiotów komercyjnych przy jednym projekcie. Jednak proporcje udziału tych podmiotów moga być różne. Dlatego członków Wspólnoty zaszeregować można do trzech kategorii określających dominację sektora publicznego bądź komercyjnego w projektach badawczych.

W czterech państwach Unii jednostki publiczne są stroną dominuja. W Wielkiej Brytanii w analizowanych projektach uczestniczyło łączenie 39 podmiotów. 26 z nich to uniwersytety; dwa z nich: University of Cambridge i University of Edinburgh, są ośrodkami wyraźnie dominującymi na poziomie krajowym, gdyż brały udział odpowiednio w 5 i 6 projektach. Pozostałe państwa to: Malta, Portugalia i Słowacja. Liczba możliwych jednostek zarówno publicznych, jak i komercyjnych, jest w wypadku Malty ograniczona terytorialnie. I choć stosunek podmiotów komercyjnych do publicznych wynosi 1:1 (University of Malta i Acrosslimits), to jednak uniwersytet brał udział w 6 z 7 analizowanych projektów. Dlatego bezsprzecznie stwierdzić można, że podmiot publiczny jest w tym 
kraju stroną dominującą w międzynarodowych projektach badawczych. Podobnie w Portugalii 5 z 6 analizowanych podmiotów należało do sektora publicznego. W tych trzech państwach wyraźnie widać tendencję by sektor ten był dominującym pod względem udziału w międzynarodowych projektach badawczych. Z kolei na Słowacji w projektach uczestniczyło 5 podmiotów publicznych i 3 komercyjne, z czego jedna firma brała udział w dwóch projektach. Tym samym Słowacja choć procentowo wykazuje większy wkład podmiotów publicznych, to jednak zbliża się do modelu, gdzie proporcje uczestnictwa są zbliżone.

Sytuację taką obserwujemy w kolejnych pięciu krajach, w których stosunek liczby podmiotów komercyjnych do jednostek publicznych oscylował w granicach 50\%. Krajami tymi były: Austria (odpowiednio 5:6), Czechy (odpowiednio: 8:7), Dania (odpowiednio: 3:3), Litwa (odpowiednio 7:6), Szwecja (odpowiednio 4:4). Taka proporcja wydaje się być najkorzystniejsza w długoterminowej perspektywie działań, gdyż determinuje ścisłą współpracę z przemysłem. Idea transferu wiedzy z ośrodków akademickich do sektora komercyjnego w takim modelu spełnia się najlepiej. Wiadomo, że proces badawczy w przypadku połączenia technologii i języka wymaga symbiozy strony merytorycznej i technologicznej. Na dalszym etapie powstały produkt należy odpowiednio uformować, dostosować do potrzeb rynku, wypromować i w efekcie końcowym sprzedać. Dlatego też konieczna jest obecność podmiotów komercyjnych.

Niewymienione wyżej kraje, stanowiące większość, bo aż 18 państw członkowskich, należą do ostatniej kategorii, w której podmioty komercyjne są stroną dominująca. Choć sytuacja taka może wynikać z natury realizowanych projektów wymagających zaangażowania specjalistycznych firm dysponujących odpowiednią technologia, to jednak udział podmiotów publicznych jest w niektórych przypadkach zdecydowanie mniejszy. Sytuacja taka jest niekorzystna z punktu widzenia prowadzonej polityki edukacyjnej i naukowo-badawczej w danym kraju, gdyż sugeruje niewystarczająca alokację środków finansowych w tym sektorze. Część podmiotów komercyjnych prowadzi bowiem również działalność naukowo-badawcza, a wchodząc w międzynarodowe konsorcja badawcze pozyskują dodatkowy kapitał (ludzki i finansowy), pozwalający na dalszą działalność. Kształtuje się wówczas sytuacja, w której podmiot publiczny (uczelnia, instytut, ośrodek naukowo-badawczy) nie mając wystarczającego źródła finansowania na prowadzenie badań nie rozwija się i nie uczestniczy w międzynarodowych projektach, tracąc swoją pozycję, pracowników naukowych i prestiż na rzecz podmiotów komercyjnych. Dlatego w dłuższej perspektywie działania na szczeblu ministerialnym powinny być ukierunkowane w stronę wspomnianego modelu, gdzie ilość podmiotów publicznych i komercyjnych współpracujących ze sobą jest zbliżona. Wydaje się, że wówczas idea transferu wiedzy akademickiej do sektora przemysłowego realizuje się najpełniej. 


\section{Dyskusja i wnioski}

Autorki swoje zainteresowanie tandemem język - technologia zawęziły do rozważań nad rozwiązaniami z obszaru zastosowania ICT w nauczaniu języków obcych i technologii językowych. Wybór sposobu oceny, a więc analiza 75 projektów unijnych, których fundamentem było połączenie języka i technologii, pozwolił na wyciagnięcie wniosków co do zaangażowania poszczególnych państw członkowskich w omawianą problematykę.

Zauważono, że zakres tematyczny projektów ma charakter edukacyjny i naukowy. W pierwszych latach po roku 2000 znaczna część realizowanych projektów koncentrowała się na wypracowaniu metodologii nauczania języków obcych, zastosowania narzędzi ICT jako stałego elementu w procesie edukacyjnym oraz uruchamianiu platform e-learningowych. Nadrzędnym celem projektów była realizacja i promocja wielojęzyczności i wielokulturowości UE. Projekty dotyczące technologii językowych pod względem ilości były traktowane raczej drugorzędnie, choć efekty prowadzonych badań (5PR i 6PR) znalazły już swoje praktyczne zastosowanie. Proporcje uległy zamianie wraz z ogłoszeniem 7PR, a następnie redefiniowaniem priorytetów na kolejne lata, które wyraźnie określały kierunek działań naukowobadawczych Wspólnoty. Rozwój technologii językowych stał się jednym z ważniejszych elementów prac nad technologiami informacyjno-komunikacyjnymi.

Największym beneficjentem omawianych tu projektów są Niemcy. Kraj ten był zdecydowanie najaktywniejszym uczestnikiem zespołów badawczych. Aktywność pozostałych państw, zaszeregowano do następujących grup:

I. Niemcy, Hiszpania, Wielka Brytania;

II. Czechy, Finlandia, Francja, Grecja, Holandia, Włochy;

III. Austria, Belgia, Bułgaria, Dania, Irlandia, Litwa, Łotwa, Polska, Rumunia, Słowenia, Szwecja, Węgry;

IV. Cypr, Estonia, Malta, Luksemburg, Portugalia oraz Słowacja.

Z kolei pod względem podmiotów biorących udział w przedsięwzięciach, najlepszy model prezentuja: Austria, Czechy, Dania, Litwa oraz Szwecja. W krajach tych stosunek liczby podmiotów komercyjnych do publicznych oscylował w granicy $50 \%$. Odsetek taki wskazuje na dobrą współpracę między sektorem edukacyjnym a przemysłowym, co z kolei stanowi praktyczne odzwierciedlenie postulatów strategii lizbońskiej.

Przedstawiona analiza ukazała stopień zaangażowania konkretnych państw UE w obszar prac nad językiem i technologia. Daje to podstawę do dalszych badań i analiz, w których jednym z kierunków może być zastosowanie wybranych narzędzi do nauczania języka obcego dorosłych. Co więcej, można zbadać efektywność takiego narzędzia oraz opracować sposób doboru do tej konkretnej grupy. Z kolei badania na skalę europejską mogłyby koncentrować się na roli narzędzi ICT w nauczaniu języków obcych dorosłych w konkretnym kraju. Takie podejście 
wymaga bardziej szczegółowej analizy i danych, jednak można założyć, że otrzymane wyniki byłyby wartościowe w tym właśnie kontekście.

Zaprezentowane badanie jest pierwszym krokiem do stwierdzenia, w których krajach zastosowanie technologii do kształcenia językowego, w tym kształcenia dorosłych, jest najbardziej prawdopodobne. Państwa wykazujące największą aktywność posiadają rozwiązania gotowe do zastosowania zarówno w przemyśle, jak i sektorze edukacyjnym. Jednakże stopień tego zastosowania jest nieznany. Określenie właściwych narzędzi, sposobu ich użycia oraz efektywności, wymaga dalszych badań i analizy materiału.

\section{BIBLIOGRAFIA}

Bayne S., Ross J. 2007, The 'digital native' and 'digital immigrant': a dangerous opposition, Annual Conference of the Society for Research into Higher Education (SRHE) 12.2007, http://www.malts.ed.ak.uk. DW: 01.06.2011.

Directorate General Education and Culture at the European Commission 2002, The Impact of Information and Communications Technologies on the Teaching of Foreign Languages and on the Role of Teachers of Foreign Languages, http:/ / ec.europa. eu/education/policies/lang/doc/ict.pdf. DW: 01.03.2010.

Education and Culture Executive Agency (EACEA) 2009, Study on the Impact of Information and Communications Technology (ICT) and New Media on Language Learning, Ellinogermaniki Agogi, http://eacea.ec.europa.eu/.../study_ impact_ict_new_media_language_learning/executive_summary_en.pdf. DW: 02.07.2010.

Euro Languages Net, Lingua Products Fair, http:/ / www.euro-languages.net/sdm/ ?Command=LPF. DW: 01.06.2010.

Eurobarometr 243 2005, Europejcaycy $i$ ich jezyki. Podsumowanie, http://ec.europa. eu/public_opinion/archives/ebs/ebs_243_sum_pl.pdf. DW : 29.08.2008.

European Commission, Cordis: 7FP: ICT: Language Technologies, http:/ / cordis.europa. eu/fp7/ict/language-technologies/portfolio_en.html. DW : 01.06.2010.

European Commission ICT Research in FR7, ICT Challenge 4: Digital Libraries and Content - Intelligent Information Management: Work Programme for 2009-2010, http:/ / cordis.europa.eu/fp7/ict/content-knowledge/fp7_ en.html. DW: 25.09.2010.

European Commission ICT Research in FR7, Language Technologies: ICT Work Programme 2011-2012, http://cordis.europa.eu/fp7/ict/language-technologies/ related-docs_en.html. DW: 25.09.2010.

Growth, Competitiveness, Employment: The Challenges and Ways Forward into the 21st Century - White Paper, Parts A and B. COM (93) 700 final/A and B, 5 December 1993. Bulletin of the European Communities, Supplement 6/93, http:/ / aei.pitt.edu/1139/. DW: 01.10.2010.

Guo R. X., Dobson T., Petrina S. 2008. Digital Natives, Digital Immigrants: An Analysis of Age and ICT Competency in Teacher Education, Journal of Educa- 
tional Computing Research, v38 n3 s. 235-254, 2008 http://baywood. metapress.com/link.asp?target $=$ contribution\&id $=\mathrm{Q} 4565 \mathrm{NG} 624514844$. DW: 01.06.2011.

High-level Group chaired by European Commissioner Martin Bangemann, Europe and the Global Information Society Bangemann report recommendations to the European Council, http://ec.europa.eu/archives/ISPO/infosoc/backg/bangeman. html\#action_plan. DW: 01.10.2010.

Holton, D. 2010. The Digital Natives/Digital Immigrants Distinction Is Dead, Or At Least Dying, EdTechDev - developing educational technology, http://edt echdev.wordpress.com/2010/03/19/the-digital-natives-digital-immigrant s-distinction-is-dead-or-at-least-dying/. DW: 01.06.2011.

International Cooperation, Participation in EU Education and Training Programmes, http://internet.ktu.lt/en/kut/trysiai/LLP_projects.html. DW: 01.06.2010.

Kennedy, G., Dalgarno, B., Bennett, S., Judd, T., Gray, K. \& Chang, R. 2008. Immigrants and natives: Investigating differences between staff and students' use of technology. (w:) Hello! Where are you in the landscape of educational technology? Proceedings ascilite Melbourne 2008, http://www.ascilite.org.au/conferences/ melbourne08/procs/kennedy.pdf. DW: 08.03.2010.

Prensky, M. 2001. Digital Natives, Digital Immigrants, On the Horizon, MCB University Press, Vol. 9 No. 5, October 2001 http://www.marcprensky.com/. DW: 09.03.2010. 